\title{
El movimiento de Jesús después de su resurrección y antes de la Iglesia. Claves hermenéuticas para interpretar los Hechos de los apóstoles (II)
}

\author{
Pablo Richard, \\ Departamento Ecuménico de Investigaciones, \\ San José, Costa Rica.
}

\section{Manifestación de la comunidad en Jerusalén: 3, 1 - 4, 31}

Tenemos aquí un narración en cuatro actos. Lucas hace teología narrativa y, por ello, la fuerza del relato está en su totalidad. Se rompe el relato y la teología del relato cuando interpretamos cada parte por separado. Este relato ha sido compuesto por Lucas a partir de información histórica, posiblemente transmitida por tradición oral. Pero el conjunto, respetando la historia y la tradición, es una composición redaccional, donde cada elemento histórico del relato adquiere una dimensión simbólica. El autor está creando un paradigma histórico para interpretar la vida de la primera comunidad en Jerusalén y proponerla como modelo para la Iglesia de su tiempo y del futuro.

Curación de un tullido: 3, l-10. La historia comienza con un hecho concreto. Pedro y Juan suben al templo a la hora del sacrificio de la tarde (como a las $3 \mathrm{p}$. $\mathrm{m}$.), como si estuvieran integrados a la organización litúrgica del templo. Son hombres del templo (cfr. 5,12 b y 5,42 ). Pero un pobre se les atraviesa en el camino y les cambia el programa. Hay un encuentro profundo de los apóstoles con el hombre tullido que todos los días llevan y ponen en la puerta del templo (como si fuera un objeto). Este encuentro se expresa en la mirada: el tullido ve a Pedro, Pedro fijó en él la mirada y le dijo míranos y el tullido los miraba con fijeza. Podemos decir que hay un encuentro profundo entre la Iglesia (representada por Pedro) y el pobre (representado por el tullido). El tullido representa también al pueblo de Israel, que está tullido por la práctica de la ley y por el templo (así Rius-Camps). Pedro no tiene oro ni plata, sino únicamente la fuerza del resucitado 
y su Espiritu. Con esta fuerza ordena al tullido que camine; pero no sólo le ordena, sino que también le da la mano. La liberación del tullido es una verdadera resurrección: cobran fuerza sus pies y tobillos, da un salto, se pone de pie, camina y entra con ellos en el templo andando, saltando y alabando.

Discurso de Pedro: 3, //-26. Pedro habla en el templo, prescindiendo de las autoridades de Israel; habla con extraordinaria auloridad, como maestro, como profeta, como jefe del pueblo. Se insiste en la participación de "todo el pueblo" (vv. 9 y 11) y es a ese pueblo a quien habla. Pedro invoca al Dios de Abraharn, Isaac y Jacob, interpreta a Moisés y a todos los profetas. Da la impresión que Pedro se ha apoderado del pueblo y del templo, y como jefe lo orienta en la uradición profética de Israel.

Pedro comienza deshaciendo un mal entendido: el tullido ha sido sanado, no por el poder mágico de Pedro, sino por la fe en el nombre de Jesús (v. 12 y v. 16 que hacen de inclusión a la primera parte del discurso). En el centro (vv. 1315) está el testimonio de Pedro: el pueblo entregó a Jesús, renegó de él ante Pilato y lo mat6, pero Dios lo resucito. Pedro y los apóstoles son testigos de esto. La resurrección necesita del testimonio de los apóstoles; es el testimonio el que da fuerza histórica a la resurrección. Jesús aqul es designado como el siervo, el santo y el justo, el jefe que lleva a la vida, lo que quizás representa una cristología antigua. La muerte de Jesús es presentada como un asesinato realizado por el pueblo judío. Todavfa no aparece la reflexión teológica sobre el sentido salvífico de la muerte de Jesús. Lucas disculpa a Pilalo, no para congraciarse con el imperio romano, sino para darle un sentido histórico a la muerte de Jesús, en el contexto del pueblo de Israel.

La segunda parte del discurso (vv. 17-26) agrega motivos nuevos y más elaborados. Se insiste mucho en los profetas (seis veces aparece la palabra "profeta"). Los profetas han anunciado un mesías sufriente, pero por su resurrección ha instaurado "tiempos de consolación" (kairoi anapsyxeos) y "tiempos de restauración" (chronoi apokasastaseos) de todas las cosas (vv. 20-21); esos tiempos sólo pueden realizarse si el pueblo de Israel se convierte y se arrepiente de sus pecados. Mientras el pueblo no se convierta, el "cielo retiene a Jesús". Aquí no se está hablando de la segunda venida de Jesús, sino del tiempo de la resurrección (tiempo de consolación y restauración), que incluye su exaltación, la venida del Espíritu, la predicación apostólica y su parusfa. Este tiempo de la resurrección es el tiempo presente y es el pecado del pueblo el que impide su plena realización(10). Jesús es el profeta anunciado por Moisés (v. 22) y este

10. Muchos autores opinan que Lucas retrasó la parusía e inventó el período de la Iglesia. La Iglesia primitiva esperaba la segunda venida de Jesús pronto. Como no sucedió nada, se dejo la parusla para el final y se descubrió el tiempo actual como el período de la Iglesia: A esta creación teológica, que serfa fundamentalmente de Lucas, se le llama "protocatolicismo", lo que conlleva una radical des-escatologización de la Iglesia 
profeta es una amenaza, pues el que no lo escuche será eliminado del pueblo. Todos los profetas han anunciado estos días de resurrección, consolación y restauración. Jesús ha resucitado, en primer lugar, para el pueblo de Israel, para bendecirlo y para apartar a cada uno de sus iniquidades. Es así como Pedro llama a la conversión del pueblo y a su arrepentimiento. Pedro presenta la conversión a Jesús, el mesías muerto y resucitado, como la opción más coherente con toda la tradición profética de Israel. La comunidad que sigue a Jesús es el verdadero pueblo de Israel, el auténtico pueblo de Dios fiel a sus promesas. Pedro habla al pueblo que ha sido testigo de la resurrección del tullido y que escucha ahora el testimonio de Pedro sobre la resurrección de Jesús. Pedro habla en el templo, como el verdadero jefe del pueblo; su testimonio será interrumpido por las autoridades históricas del templo.

Represión de las autoridades del templo y testimonio de Pedro: 4, I-22. El discurso de Pedro es interrumpido por las autoridades judías: los sacerdotes, el jefe de la guardia del templo y los saduceos, es decir, el poder religioso, militar y político de Jerusalén. Les molesta que Pedro y Juan enseñen al pueblo y anuncien la resurrección en la persona de Jesús. Las autoridades se consideran los auténticos jefes de Israel y no toleran que otros enseñen al pueblo. No pueden tolerar que Pedro se constituya en maestro y profeta de Israel. Además rechazan radicalmente que se anuncie la resurrección. No se trata aquí de un tema puramente teologico (que no agradaría a los saduceos, quienes no creían en la resurrección), sino de un tema profético y apocalíptico popular, cuyo eje era la reconstrucción de la esperanza del pueblo. La resurrección de Jesús se inscribe en esa tradición apocaliptica popular, tradición amenazante para las autoridades del templo. Por otro lado, muchos del pueblo que oyeron la Palabra, creyeron y el número de los discípulos llegó a 5 mil hombres. El pueblo de Israel sigue a Pedro, como a su verdadero jefe, en contra de las autoridades constituldas del templo. Aquí aparece ya un tema que se desarrollará en el relato que sigue.

El testimonio de Pedro (vv. 5-12) se da en un contexto institucional de alta jerarquia: en Jerusalén (nombre sacro de la ciudad), en el sanedrín (cfr. v. 15), con las más altas autoridades: jefes, ancianos, escribas y todos los sumosacerdoles (cuatro son presentados por su nombre). Pedro y Juan son interrogados formalmente sobre su poder que y en nombre de quién han actuado. La misma pregunta hicieron a Jesús en el templo (Lc 20, 1-2). La respuesta de Pedro es también muy formal y con autoridad, pues habla "lleno del Espiritu Santo(11).

y una pérdida de toda dimensión apocalíptica. Esta posición es falsa. Para Lucas, como para la teología apocalíptica, el hecho escatológico fundamental es la resurrección de Cristo y esto le da un carácter escatológico a la Iglesia durante todo el tiempo presente. 11. El adjetivo "lleno" (plestheis) indica cualidad permanente: Pedro es un hombre del Espíritu y como tal está hablando. En 6, 5 se dirá lo mismo de Esteban. 
Ahora, Pedro no se dirije al pueblo, sino a las autoridades: "jefes del pueblo y ancianos". Su testimonio es claro y directo: el tullido ha sido sanado por el nombre de Jesús, a quien los jefes del pueblo crucificaron y Dios resucit6 de entre los muertos. Jesús ha llegado a ser la piedra angular, que los jefes de Israel, como constructores, habían rechazado. La salvación sólo puede darse en el nombre de Jesús. Este testimonio es un enfrentamiento directo con las autoridades de Israel y la proclamación explícita de una conducción alternativa. Es, en realidad, un testimonio "increíble", y surge la duda de si es históricamente de Pedro o fue construfdo por Lucas en el contexto de su Iglesia, en los años 90. Pienso que las dos cosas son posibles: Lucas usa tradiciones históricas, surgidas de hechos históricos, pero las recuerda y las re-construye redaccionalmente en función de su propia situación histórica y eclesial.

La reacción de los jefes del sanedrín expresa su total derrota frente a Pedro y Juan (vv. 13-17). Lucas usa tres verbos en imperfecto (acción prolongada y persistenle en el presente): se admiraban, reconocían y no tenían nada que replicar (el sujeto de los tres verbos es el mismo: los jefes del sanedrín). Se admiraban viendo la valentía (parresia) de Pedro y Juan y sabiendo que eran hombres sin instrucción ni cultura (agrammatoi kai idiotai). Reconocían que Pedro y Juan eran discípulos de Jesús y al mismo liempo veían de pie junto a ellos al hombre sanado. Y la conclusión es obvia: no senian nada que replicar. Los jefes del sanedrín se sienten derrotados por la valentía y el poder de los pobres, representados aquí por los discipulos Pedro y Juan. Como no pueden negar la evidencia de la curación del tullido, recurren a lo único que pueden manejar: la amenaza. No se niega el signo, pero se reduce al silencio a sus testigos. Es impresionante la similitud con Juan $11,45-54$ (se reconoce el milagro-señal realizado por Jesús, pero deciden matarlo para que no tenga impacto en el pueblo).

El segundo testimonio de Pedro y Juan es más radical: "disciernan si es justo delante de Dios escucharlos a ustedes más que a Dios, puesto que nosolros no podemos no hablar sobre lo que vimos y oímos" (Iraducción literal de los vv. 19-20). La función del sanedrín es discernir los hechos y Pedro los llama a ejercer esa función, pero la respuesta de los jefes, escribas y ancianos de Israel es otra vez la amenaza.

\section{Reunión de la comunidad: 4, 23-31}

Tenemos aquí el testimonio quizás más antiguo sobre una reunión litúrgica de la comunidad cristiana. Lucas posiblemente utiliz6 una fuente antigua (sobre todo para la oración: vv. 24b-30), pues muchos elementos de ella no son lucanos. El texto refleja una comunidad perseguida a causa de la Palabra y que está decidida, a pesar de la persecución, a seguir predicando la Palabra con toda valentía. Es la reunión de una comunidad más bien misionera y carismática, no tanto una comunidad establecida, como sería el caso en 2,42 . El eje aquI es la 
predicación de la Palabra, no tanto la didaje, la koinonia y la eucaristía por las casas. No es tampoco la asamblea de los 5 mil creyentes, sino más bien la reunión de una comunidad itinerante y evangelizadora, que se reúne en medio de las persecuciones.

La estructura subyacente en la reunión es la siguiente:

(1) Rcunión y análisis de lo sucedido (v. 23)

(2) Oración (impregna toda la reunión)

(3) Lectura de la Palabra de Dios: Salmo 2, 1-2

(4) Comentario (en comunidad y en oración) de la Palabra (vv. 27-28)

(5) Oración de petición: predicar la Palabra con valentía y poder (vv. 29-30)

(6) Experiencia comunitaria del Espíritu Santo (v. 31a)

(7) Acción: predicaban la Palabra de Dios con valentía (v. 31 b)

Lucas da testimonio de la reunión de la comunidad y construye un paradigma de comunidad misionera. Ningún elemento de este paradigma puede faltar en las reuniones futuras de las comunidades evangelizadoras (itinerantes y carismáticas).

Llama la atención la unidad de los apóstoles con la comunidad: comparten lo sucedido, rezan e interpretan juntos la Palabra de Dios, todos viven la misma experiencia del Espíritu Santo y todos se comprometen en la continuidad de la predicación con valentía de la Palabra de Dios. La interpretación del Salmo 2 es tradicional, aplicada al triunfo del mesías, pero su aplicación a la pasión no es usual. La alianza de Herodes con Pilato está en la tradición del evangelio de Lucas (cfr. Lc 23, 1-25). Herodes desprecia a Jesús (como desprecia todo movimiento mesiánico y profético popular), pero Lucas más bien disculpa a los dos en su reponsabilidad por la muerte de Jesús. La conspiración de Herodes y Pilato contra Jesús y la alianza de las naciones no judías (ethnos) y los pueblos judíos (laos) contra el meslas debió ser un motivo tradicional pre-lucano. La comunidad no pide que cese la represión, sino que Dios conceda a sus misioneros seguir predicando la Palabra de Dios con valentía (parresia, término técnico que designa la actitud del aquel que predica y da testimonio). La expresión "tu santo siervo Jesús" también pertenece a la tradición antigua que utiliza Lucas. El v. 31 es importante: "retembló el lugar donde estaban reunidos y todos quedaron llenos del Espínitu Santo". Hay aquí una semejanza con pentecostés: el temblor es paralelo al viento impetuoso de 2, 1 y, en ambos casos, "lodos quedan llenos del Esplritu Santo" (eplesthesan). Pentecostés no fue un hecho aislado: se vivi6 al comienzo (2, 1-13), se vivió en la comunidad misionera y también se renovará en casa del centurión romano Cornelio $(10,44-46)$. Lucas mismo relaciona ambos hechos: "cayó sobre ellos el Espiritu Santo como al principio habfa caído sobre nosotros" (11, 15; véase 15,8$)$. El terremoto es un signo muy común en la 
literatura apocalíptica para expresar la presencia divina y su fuerza transformadora de la historia. Podemos decir que la oración de la comunidad hizo "lemblar" a la ciudad de Jerusalén y al templo.

\section{Consolidación de la comunidad: 4, 32 - 5, 16}

Los dos sumarios que tenemos aquí, igual que en la sección 1, 12 - 2, 47, enmarcan la narrativa, en este caso sobre Bernabé, Ananías y Safira. Ese es el marco en el cual ahora interpretaremos los dos relatos concretos de la presente sección. La comunidad vive ahora una situación nueva después de su enfrentamiento con las autoridades del templo. El primer sumario de esta sección (4, 32-35) está en continuidad con el sumario de 2, 42-47. El v. 32 del cap. 4 prolongan 2, 44: se afima la koinonia como unidad subjetiva de alma y corazón y la unidad objetiva de tener todo materialmente en común. Los vv. 34-35 del cap. 4 prolongan 2, 45: se vendían los bienes y el dinero se repartía según la necesidad de cada uno. En el primer sumario lo que se vende son posesiones y bienes en general, ahora se dice más concretamente que venden campos o casas. No se trata sólo de gente rica que se desprende de sus bienes, sino de discipulos que dejan todo aquello que los ata a un lugar (tierra y casa). Hay dos novedades importantes en 4, 34-35: "no había entre ellos ningún necesitado" y el precio de la venta "lo ponían a los pies de los apóstoles". Estas dos expresiones muestran una comunidad con una organización interna más desarrollada. Ya no se trata sólo de la satisfacción de necesidades, sino de la eliminación de la pobreza en la comunidad. Esto exige a los apóstoles cumplir el rol de administradores. Poner algo a los pies de alguien significa reconocer su autoridad a quien se le encomienda la administración de algo. Esta expresión se repite tres veces: 4, 35.37 y 5, 2. Es la administración de la koinonia. En el centro del sumario está lo fundamental: "Los apóstoles daban testimonio con gran poder de la resurrección de Jesús" (v. 33). Este versículo retoma el eje central de los Hechos, que ya apareció en 1,$8 ; 2,32$ y 3,15 y es el punto culminante del testimonio de Pedro y Juan ante el sanedrín.

El relato sobre Bernabé: 4, 36-37. Después del sumario general tenemos dos relatos concretos: uno positivo sobre Bemabé y otro negativo sobre Ananlas y Safira. Bernabé es una persona muy importante en los origenes del cristianismo. Su nombre es José, pero los apóstoles lo llaman Bernabé, que significa hijo de la consolación o exhortación. José es considerado por su habilidad ("hijo de") para consolar, exhortar, profetizar. Algunos traducen Bernabé como "hijo de la profecla". En todo caso es considerado como un hombre del Espíritu. Bernabé es levita y originario de Chipre. Es decir es judro de la diáspora, de oficio levita (un sacerdocio de segundo orden, de la tribu de Levf, hombre consagrado a Yahvé). Bernabé no sólo está de paso como peregrino en Jerusalén, sino que ahí compró un campo. Muchos judlos de la diáspora compraban un campo en Jerusalén por motivos religiosos, para estar más ligados a la tierra santa. Es 
curioso que un levita tenga un campo, pues según Deuteronomio 10, 9 y Números 18, 20, el levita no puede tener tierra, pues sólo Dios es su heredad. Bernabé aparece en Hechos 9, 27 presentando a Saulo a los apóstoles; en 11, 22-30, como enviado de la iglesia de Jerusalén a Antioquía; en 11, 30 y 12, 25, junto con Saulo, llevando una colecta a Jerusalén y regresando a Antioquía; en 13, 1-3, Bernabé y Saulo son escogidos por el Espíritu para la misión de la Iglesia de Antioquía (13-14); Pablo y Bemabé son enviados por la Iglesia de Antioquia a la asamblea de Jerusalén (15). En 15, 36-40 Bernabé rompe con Pablo a causa de Juan Marcos(cfr. Gal 2) y después no aparece más en el libro de los Hechos. Pablo lo menciona en 1Corintios 9, 6 como un hombre que, como él, trabaja con sus manos (¿se habría ya reconciliado con Pablo?). En Colosenses 4, 10 se dice que Bernabé es primo de Marcos. Bernabé es de Chipre, lugar de su primera misión junto con Pablo $(13,4)$, y alli se dirige después de romper con Pablo $(15,39)$.

De Bernabé dice Lucas que "tenía un campo; lo vendió, trajo el dinero y lo puso a los pies de los apóstoles" $(4,37)$. No se trata aquí primariamente del hombre rico que deja todo para ser discípulo de Jesús, a la manera como Jesús se lo exigió al joven rico: "todo cuanto tienes véndelo y repártelo entre los pobres, y tendrás un tesoro en el cielo; luego ven y sígueme" (Lc 18, 18-23 cfr. 14, 33). Aquí se trata más bien de una ruptura con el pasado. Bernabé, al vender su campo en Jerusalén, rompe con la institucionalidad judía y entra en la nueva comunidad dirigida por los apóstoles. Sobre esto volveremos más adelante en una visión de conjunto.

Ananias y Safira: 5, 1-/1. La acción de Ananías y Safira (vv. 1-2) consiste en vender una propiedad, quedarse con una parte del precio y entregar a los apóstoles la otra parte. El texto insiste dos veces en la complicidad de Safira con Ananías. El enfrentamiento de Pedro con Ananfas (vv. 3-6) es violento. Pedro piensa que Satanás Ilenó el corazón de Ananfas y que mintió al Espíritu Santo. Pedro aclara que Ananías era libre en su opción de vender y disponer del dinero. Esto es valioso como información para el lector de hoy: la venta de bienes no era obligatoria; tampoco la entrega de todo el dinero a los apóstoles. Ananías no alcanza a decir nada: oye, cae y expira. El temor se apodera de todos y los jóvenes entierran a Ananías. El enfrentamiento con Safira (vv. 7-10) es paralelo al anterior. Lo nuevo es que Pedro interroga a Safira y ésta tiene la oportunidad de responder, desgraciadamente sólo para confirmar la mentira. Pedro dice ahora que ambos "han puesto a prueba (han tentado) al Espíritu del Señor". Igualmente son los jóvenes quienes entierran a Safira. En la conclusión (v. 11) tenemos un elemento llamativo: aparece por primera vez en los Hechos la palabra "iglesia": "Un gran temor se apoderó de toda la Iglesia y de todos cuantos oyeron esto".

¿Qué significa este relato de Bernabé, Ananfas y Safira? El significado aparente del texto es ilusirar, con un ejemplo positivo y negativo, la vivencia de la koinonia en la primera comunidad. Pero este significado plantea muchos 
interrogantes: ¿por qué Lucas recuerda el hecho tan negativo de Ananías y Safira en el relato altamente positivo de las primeras comunidades en Hechos 1-5? Los tres personajes, ¿representan grupos diferentes dentro de la comunidad? ¿Cómo explicar la muerte tan violenta de los esposos? ¿Qué sentido tiene la participación de los jovenes? ¿Por qué Lucas introduce justamente aquí el término "iglesia"? Intentemos una interpretación más profunda por detrás del texto.

El enfrentamiento con las autoridades del templo (4, 1-22) ha puesto a la comunidad en una situación diff́cil. La reunión de la comunidad $(4,23-31)$, especialmente la renovación de pentecostés y el temblor que estremece el lugar donde están reunidos $(4,31)$, ha revelado la nueva situación de la comunidad. Se hace necesario una consolidación. Este es el sentido de la sección 4, 32 - 5, 16 que aquí estamos analizando. La presentación de Bernabé, y luego de Ananías y Safira, nos hace sospechar, dentro del contexto, que Lucas aquí veladamente ya está introduciendo al lector en la confrontación posterior de los dos grupos de la comunidad presentados en 6, 1: los helenistas y los hebreos. Bernabé representaría aquí la corriente que posteriormente configurará al grupo de los helenistas, que serán los protagonistas principales de la sección de Hechos que va del capítulo 6 al 15, donde justamente también se concentra la actividad de Bernabé. Ananías y Safira reprentarían la corriente que posteriormente configurará el grupo de los hebreos. Más arriba, hemos interpretado la venta del campo de Bernabé, no fundamentalmente como un acto de desprendimiento, sino como una ruptura con el pasado. Recordemos la acción contraria de Judas, que con el precio de su iniquidad compró un campo $(1,18)$. El campo, en el caso de Judas y Bernabé, simboliza la integración a la institucionalidad judía. Judas traiciona a Jesús, rompe con el grupo de los doce apóstoles y vuelve atrás. Bernabé rompe con el pasado y se integra a la comunidad apostólica. En el caso de Ananías y Safira, el hecho de retener parte del dinero de la venta del campo, revela que los esposos están divididos: por un lado quieren participar de la actitud general de venderlo todo y traer el precio de la venta a los apóstoles; por el otro lado, relienen una parte del dinero, para continuar su vida y su proyecto económico anterior. Quieren participar de la vida de la nueva comunidad, pero mantener su siluación económica anterior y su posición tradicional dentro de la institucionalidad judra. Muchos encuentran un paralelismo entre esta historia y la historia de Acan en Josué 7, 1-26. Este se queda con parte del botín y es apedreado y muerto, pues por su culpa el pueblo es derrotado. El botín era parte de lo consagrado con anatema. El anatema tenía como objetivo impedir la participación del pueblo de Dios en el sistema económico y social de las ciudades cananeas. Quedarse con parte del botín era complicidad con el sistema que están justamente destruyendo. El verbo en ambos pasajes es el mismo: "retener para sí" (nosphizo). El relato de Ananías y Safira, liene esta connotación violenta del relato de Acán. Igual que Acán, Ananías y Safira no rompen con el sistema con el cual la comunidad apostólica ha decidido romper. En momentos de conso- 
lidación de la comunidad, la actitud de Ananfas y Safira implicaba la muerte de la comunidad, como la actitud de Acán significó la derrota del pueblo de Dios, en tiempos de Josué.

Pedro interpreta la actitud de Ananías como obra de Satanás y mentira al Espíritu Santo: "Satanás llenó tu corazón para mentir al Espíritu Santo" (v. 3). ¿De qué mentira se trata? Hay una mentira manifiesta y oura oculta. La mentira manifiesta fue daclarar a Pedro como precio de venta el precio entregado y ocultar lo que se dejó para sí. Pero esta mentira no justifica la violencia del relato. Por eso sospechamos aquí otra mentira que Lucas oculta detrás del texto: la mentira de aparecer como miembros de la nueva comunidad, sin romper con la vieja institucionalidad judía del templo y la ley. Esta será la actitud del grupo de los hebreos, que aparece posteriormente en el relato. Es la actitud mentirosa de los cristianos que se aferran al pasado y sólo aparentemente participan de la nueva comunidad de Jesús. No se tiene todavía total confianza en la comunidad. Se acepta el nuevo proyecto, pero se mantienen las viejas estructuras, por si acaso el nuevo proyecto fracasa. La vida de la primera comunidad cristiana, tal como se ha descrito en los sumarios $(2,42-47$ y $4,32-35)$, exige entrega total. El relato de Lucas en esta sección $(4,32-5,16)$ ya está planteando que el proyecto de la primera comunidad implica una ruptura con la institucionalidad judía del templo y de la Ley. No se puede seguir en ambos proyectos a la vez, ni siquiera aparentar estar en los dos proyectos. Es por eso que en el relato de Lucas aparece aquí -en 5, 11- por primera vez la palabra "Iglesia". Ya Lucas identifica la comunidad apostólica como Iglesia, como asamblea diferente y distinta de la asamblea del templo. La nueva Iglesia se reúne todavía en el templo, pero no ya para el culto, sino utilizando el espacio del "pórtico de Salomón" (v. 12b). Lucas distingue claramente entre la nueva comunidad, la Iglesia, que se reune en el pórtico de Salomón, y el pueblo de Israel; el pueblo habla de la comunidad con elogio, pero no se atreve a juntarse con ella (v. 13). La represión de las autoridades del templo ha provocado este miedo en el pueblo de pertenecer a la comunidad de Jesús. La consolidación de la comunidad exige que se elimine esta actitud como obra de Satanás y mentira al Espíritu Santo.

¿No es aquí el método utilizado por Pedro un método violento contrario al Espíritu de Jesús? Todo depende de la interpretación. Si interpretamos 5, 1-11 como un juicio, donde Pedro es el juez que dicta sentencia y condena a muerte, entonces tendramos aquí el inicio fundante de toda violencia jerárquica y autoritaria en la Iglesia. Pero no se trata de eso. En este texto no hay ni juicio ni condena a muerte por parte de Pedro. La intención del relato es otra. Si se observa la abundancia de términos económicos en esta sección: posesión de campos y casas, venta y precio de venta, entregar o retener dinero, adminisirar (poner a los pies de alguien), lo económico define aquí la identidad religiosa institucional: templo o Iglesia (comunidad de Jesús). En este contexto entra Satanás, que simboliza aquí el poder del pecado. Satanás induce a Ananfas a 
retener dinero para asegurar una opción institucional económico-religiosa. La fuerza del pecado actúa especialmente en el ámbito de lo económico-religioso y lleva a la mentira y la muerte. El texto de Lucas nos está revelando cómo en el campo económico-religioso Satanás nos conduce a la mentira y la muerte. No es Pedro el que impone aqul el régimen del terror, sino el dinero y sus opciones religiosas. Es el amor al dinero, y al estatus económico y religioso que este dinero impone, lo que mata a Ananías. Se repite aqui la historia de Judas, en quien también "entró Satanás" (Lc 22, 3), traicionó a Jesús y "compró un campo con el precio de su iniquidad" (Hech 1, 18), luego cayó de cabeza en su propio campo y se mato. Aparece el vínculo estrecho entre campo, dinero, Salanás y muerte. Ni Jesús mató a Judas, ni Pedro a Ananías. Los mató el poder de muerte del dinero.

¿Fue el pecado de Safira el mismo que el de Ananías? Llama la alención que Lucas diferencia explícitamente tanto la acción como la intención de los dos esposos(12). El que actúa es Ananías, pero su mujer está de acuerdo y sabe lo que hace Ananias (5, 1-2). Cuando Pedro la interroga sobre el monto del precio del campo vendido, Safira miente y da una respuesta falsa (v. 8). Safira entra donde está Pedro tres horas más tarde y sin saber lo que había pasado con su marido (v. 7). Esto quiere decir que Safira actúa libremente, no influenciada por la muerte de Ananías. Con esto Lucas separa y diferencia el pecado de cada uno de los dos esposos. A Ananías lo mató el poder satánico del dinero y su estatus económico-religioso, pero ¿qué mató a Safira? El texto no dice que Satanás haya entrado en su corazón ni que haya mentido al Espíritu Santo, sino que solamente dice que se puso de acuerdo con Ananías para "poner a prueba el Espíritu del Señor" (v. 9). El pecado de Safira no está en lo económico, sino en la forma de vivir su matrimonio. Lo que mata a Safira es el matrimonio patriarcal, que la somete a las intenciones de su marido. Esta forma patriarcal de matrimonio fue lo que los puso de acuerdo. El matrimonio conforme al Espíritu del Señor prohibe al esposo ejercer poder sobre la esposa y permite a la esposa ser independiente de las opciones de pecado y muerte del esposo. La esposa puede vivir como si no luviera esposo y viceversa (ese sería el sentido de 1Corintios7, 29). El pecado de Safira fue no defender su autonomía en el matrimonio y no resistir a la opción de muerte de su esposo. El matrimonio patriarcal no permitió a Safira ser libre frente a la fuerza del pecado que dominaba a su esposo. El matrimonio de Ananías y Safira representa aquí la vieja comunidad patriarcal de la ley y del templo con la cual rompe la nueva comunidad de Jesús.

Una última observación sobre los jóvenes que entierran a Ananías y Safira. En el v. 6 se los llama "los más nuevos" (neoteroi) y en el v. 10 "los jóvenes"

12. Para lo que sigue, véase Ivoni Richter Reimer, Women in the Acts of the Apostles, Minneapolis 1995, pp. 20-23. 
(neaniskoi). Lucas usa la expresión en Lucas 22, 26: "el mayor entre ustedes sea como el más joven (neoteros) y el que gobierna como el que sirve". Y en Hechos 2, 17, los jóvenes reciben el Espíritu: "nuestros jóvenes (neaniskoi) verán visiones". No cabe duda que estos jóvenes en el relato de Lucas representan la comunidad del futuro, aquella comunidad que Ananías y Safira no quieren aceptar, por su apego a la vieja institucionalidad del templo y de la ley. A ellos podríamos dirigir lo que nos dice Juan en su çarta: "les escribo a ustedes, jóvenes, porque han vencido al maligno; les escribo a ustedes, jóvenes, porque son fuertes" (1 $\mathrm{In} 2,13-14$ ). Son los jóvenes los que aseguran la consolidación de la comunidad.

\section{Reconocimiento de la comunidad: $5,17-41$}

Esta sección está en paralelo con 3,1 - 4, 31: manifestación de la comunidad en Jerusalén. Tenemos aquí la segunda persecución contra los apóstoles (5, 17 21a). Como es inusual que Lucas duplique los hechos, si lo hace, es por alguna razón importante. En la primera persecución, en 4, 1-22, son Pedro y Juan los reprimidos por el poder religioso, político y militar del templo en general. Ahora, todos los apóstoles son atacados, y lo son por un poder más individualizado: el sumo sacerdote y el partido de los saduceos. Este grupo concentra el poder político religioso, que dominaba en ese entonces el templo, y por su medio, a todo el pueblo de Israel. La acción es más violenta, pues los meten directamente en la cárcel. En Hechos tenemos tres relatos de cárcel: aquí (con los apóstoles) y en los capítulos 12 (con Pedro) y 16 (con Pablo). La memoria de la cárcel está viva en la Iglesia de Lucas, pues debió ser una experiencia corriente en los primeros tiempos. Pero la memoria de la cárcel va unida siempre a la liberación: "un ángel del Señor, por la noche, abrió las puertas de la prisión y los liberó" (v. 19). El ángel les ordena ir al templo a enseñar al pueblo, que era exactamente lo que las autoridades del templo les habian prohibido terminantemente. Pero ellos aplicaron el principio: "obedecer a Dios antes que a los hombres" (4, 19 y 5 , 29). En este relato de liberación de la cárcel, el más corto en los Hechos, ciertamente, está presente la memoria del éxodo. La Iglesia nace inspirada en la uradición del éxodo.

El sumo sacerdote y el partido de los saduceos convocan al sanedrín en pleno, es decir, a todo el senado (gerousia) de los hijos de Israel $(5,21 b-33)$. El sanedrín y el senado es lo mismo, pero Lucas usa aquf conscientemente una expresión del Exodo $(12,21)$, cuando Moisés igualmente convoca con la misma expresión a todos los representantes del pueblo. Convocado el sanedrín, llega la noticia: "los hombres que ustedes pusieron en prisión están en el templo y enseñan al pueblo" (v. 25). Hay en todo el relato una clara insistencia en que los apostoles enseñan al pueblo en el templo. Los apóstoles se han apoderado del templo, no como lugar de culto, sino como lugar de enseñanza de todo el pueblo de Israel. Los apóstoles, por orden divina, están desafiando directamente a las autoridades del templo, y eso es castigado con azotes (v. 40). Los jefes del templo, además, 
agregan una acusación contra los apóstoles, que hasta ahora no había salido en Hechos: "ustedes quieren hacer recaer sobre nosotros la sangre de ese hombre" (v. 28). Pedro en dos de sus primeros discursos acusa al pueblo de Israel de haber entregado y matado a Jesús $(2,23$ y 3, 13-15). En su presentación anterior ante el sanedrín, Pedro se dirige a los "jefes del pueblo y ancianos" $(4,8)$ y en forma directa y explícita les recrimina haber crucificado a Jesús $(4,10)$. Ahora el sumo sacerdote y los saduceos acusan a los apóstoles por haberlos acusado a ellos del asesinato de Jesús. Curiosamente, Lucas usa la fórmula que usa Mateo $(27,25)$, donde el pueblo asume la responsabilidad de la muerte de Jesús. Se trata, en realidad, de una expresión biblica tradicional.

El testimonio de Pedro y de los apóstoles (vv. 29-32) retoma un elemento fundamental de su testimonio anterior ante el sanedrín (en 4, 1-22): la obediencia a Dios. El verbo "obedecer" (peitharjeo) aparece al comienzo y al final del testimonio. Al comienzo: "es necesario obedecer a Dios antes que a los hombres" y al final "Dios ha dado el Espíritu Santo a los que le obedecen". Estas frases connotan dos cosas: el sumo sacerdote y los saduceos no representan la voluntad de Dios. La obediencia a Dios implica des-obediencia a las autoridades del templo. Los apóstoles, por obedecer a Dios y no a ellos, han recibido, por eso mismo, el Espíritu Santo. Con este testimonio, los apóstoles se declaran en total rebeldía con respecto a las autoridades del templo. Esa es la posición expresada en el primer y último versículo (vv. 29 y 32). En el centro del testimonio (vv. 30-31), Pedro y los apóstoles proponen la alternativa a su total des-obediencia: El Dios de nuestro padres resucitó a Jesús, a quienes ustedes crucificaron, y lo exaltó como jefe y salvador (arjegon kai sotera) de Israel (cfr. 30-31). La reacción del sumo sacerdote y de los saduceos al testimonio de los apóstoles es violenta: "se consumían de rabia y trataban de matarlos" (v. 33). Pedro agrega en su testimonio algo nuevo: Jesús ha sido exaltado para conceder la conversion a Israel y el perdón de sus pecados. En el evangelio, en su lestamento final, Jesús resucitado manda a sus discípulos "predicar la conversión para el perdón de los pecados a todas las naciones, empezando desde Jerusalén" (Lc 24, 47). En Hechos 5, los apóstoles están todavía en Jerusalén, en el sanedrín, y la exaltación de Jesús es lodavia únicamente para la conversión de Israel y el perdón de sus pecados. El testimonio a las naciones (ta ethne) todavía no aparece. Los apóstoles sólo cumplen con la primera parte del manda1o de Jesús (en Lc 24, 47 y Hch 1, 8).

La intervención de Gamaliel (vv. 34-39) se da cuando los saduceos llenos de rabia trataban de matar a los apostoles. Gamaliel es del partido de los fariseos, opuesto al de los saduceos, que eran los que hablan convocado el sanedrín para condenar a los apóstoles. Los saduceos tenían el control del sanedrín y del poder político-religioso en Israel. Históricamente fueron ellos los responsables de la crucifixión de Jesús. Los fariseos constitúan una agrupación más bien popular, y su influjo era mayor en las sinagogas y en los pueblos. Gamaliel era miembro del sanedrín, doctor de la ley (nomo-didaskalos), estimado por todo el pueblo. 
Es un personaje bien conocido en la literatura extra-bíblica. Era nieto de Hillel, otro gran maestro, conocido por su interpretación flexible de la ley. Gamaliel ejerció como maestro entre el 25 y 50 d. C. y aparece en Hechos como un hombre sabio y profundamente creyente, con buen conocimiento de la historia y con capacidad de discernimiento. Gamaliel argumenta a partir de los movimientos mesiánicos populares. Cita a Judas el Galileo y a Teudas, bien conocidos por los escritos de Flavio Josefo. La insurrección de Judas el Galileo se dio a partir del año $6 \mathrm{~d}$. C., cuando Arquelao fue destituído. Con Teudas hay un problema, pues el que conocemos por la historia se levantó siendo procurador Cuspio Fado (44$46 \mathrm{~d}$. C.), lo que lo sitúa alrededor de quince años después de la reunión del sanedrín que comentamos. Puede ser que Gamaliel se refiera a otro Teudas. Lo importante en todo caso es el discernimiento histórico que hace Gamaliel de los movimientos mesiánicos populares y la conclusión que saca para discernir el movimiento de Jesús, representado por los apóstoles. Si el movimiento de Jesús es humano, se destruirá; pero si es de Dios, no conseguirán destruirlo. Si condenan a los apóstoles, es posible que se encuentren luchando contra Dios. El lector tiene la impresión de que Gamaliel mismo piensa que el movimiento de los apóstoles es de Dios y que no se puede luchar contra Dios y vencer. Toda la asamblea aceptó la opinión de Gamaliel.

La intervención de Gamaliel plantea muchas preguntas: ¿habrá sido un hecho histórico real o lo compuso Lucas con tradiciones dispersas? ¿Por qué Gamaliel se pone del lado de los apóstoles y en contra de los saduceos? ¿Qué consecuencias históricas tuvo el apoyo de Gamaliel? ¿Fue positivo ese apoyo? Jesús fue condenado a muerte en el sanedrín y ahora sus apostoles salvan su vida por la intervención de un maestro de la ley fariseo. Jesús tuvo en su contra a un Judas; los apóstoles tuvieron a favor a un fariseo. No cabe duda de que la posición de Gamaliel es extraordinaria y ejemplar (ojalá los dirigentes actuales de las iglesias fueran al menos como Gamaliel, cuando se trata de juzgar los movimientos de base de la Iglesia).

Es posible que la defensa de Gamaliel sea históricamente veridica. Es coherente con la visión histórica global de los Hechos. Es posible que los apóstoles hayan resistido al sumo sacerdote y a los saduceos con el apoyo de los fariseos, con Gamaliel a la cabeza. Esto explicarfa lo que cuenta Lucas en Hechos 15, 3: "algunos de la secta de los fariseos habían abrazado la fe". El mismo Saulo era fariseo, y, según Lucas, discípulo de Gamaliel $(23,6)$. Santiago, años después, dirá a Pablo en Jerusalén: "Ya ves, hermano, cuántos miles y miles de judíos han abrazado la fe y todos son celosos partidarios de la ley" $(21,20)$. La defensa de Gamaliel y la aprobación por parte del sanedrín permitió a los apostoles seguir su enseñanza en Jerusalén. Y esto nos explicaría históricamente la situación de los apóstoles en Jerusalén: su identificación con los judíos creyentes, cuya fe no serfa demasiado distinta a la fe los fariseos. Los apostoles pertenecerfan históricamente al grupo que Lucas muy luego llamará de los bebreos $(6,1)$. Los 
saduceos aceptan la defensa de Gamaliel, pero no pueden aceptar que la desobediencia de los apostoles quede inpune. Por eso los mandan azotar y los intimidan a no hablar nunca más en el nombre de Jesús. ¿Qué efecto tuvo este castigo y prohibición en los apóstoles?

La consecuencia de todo lo anterior aparece claramente en el sumario final en 5, 42: "no cesaban de enseñar y de anunciar la Buena Nueva de Cristo Jesús cada día en el templo y por las casas". Siguen enseñando y predicando, en primer lugar, en el templo, y por el momento pareciera que sin estorbo alguno. La enseñanza por las casas nos remite al sumario en 2, 42-43. Termina la primera parte de Hechos y los apóstoles todavía no salen de Jerusalén, contradiciendo el mandato de Jesús de ser testigos en Jerusalén, Judea, Samaría y hasta el fin del mundo $(1,8)$. Sólo han realizado el testimonio en Jerusalén. El apoyo de Gamaliel y la aprobación del sanedrín deja a los apóstoles entrampados en Jerusalén. Serán otros los que llevarán la Palabra de Dios fuera de Jerusalén.

\section{II: De Jerusalén a Antioquía: 6, 1 - 15, 35}

La comunidad de los helenistas y el inicio de la misión fuera de Jerusalén: algunas claves de interpretación

Esta sección, entre la primera parte, dedicada a los doce apóstoles en Jerusalén (1-5) y la tercera parte, dedicada a Pablo (16-28), pertenece al grupo de los helenistas. Normalmente este sección no es valorada en su dimensión específica. Los siete helenistas aparecen como "servidores de las mesas", sometidos a los apóstoles, y como precursores de Pablo. En la estructura del libro, casi siempre se hace comenzar en 13, 1 la sección paulina, y se designa los capítulos 13-14 como el primer viaje misionero de Pablo. Los Hechos son presentados como los hechos de Pedro y Pablo y los helenistas desaparecen. Esta visión reduccionista distorsiona gravemente la sección de Hechos 6,1 - 15, 35 y minusvalora el protagonismo de los helenistas, tan importante en el relato de Lucas. Como veremos, la sección 13, 1- 14, 28 no corresponde al primer viaje de Pablo, sino a la primera misión de la Iglesia de Antioqua, donde Bernabé y Pablo participan enviados por la Iglesia. En la estructura presentada al comienzo, hemos dividido toda esta segunda parte en cuatro secciones tituladas Hechos de los helenistas, donde se intercalan una sección sobre los Hechos de Saulo $(9,1-31)$ y dos secciones sobre los Hechos de Pedro (9, 32 - 11, 18 y 11, 27 - 12, 25). Estas secciones intercaladas están en función del relato central sobre los helenistas. Se narra ya aquí la "conversión" de Saulo, pues Bernabé, en 11, 25 lo integra a la Iglesia de Antioquía. Igualmente el relato de Pedro y Cornelio prepara y legitima la misión de los helenistas a los griegos $(11,20)$. También el capítulo 12 , centrado en la prisión y liberación de Pedro, está enmarcado por la misión de la Iglesia de Antioquía a Jerusalén (ida en 11,27-30 y regreso en 12,25). El capítulo 15 sobre la asamblea de Jerusalén comienza en Antioquia y termina en Antioquía, lo cual es muy lógico, pues dicha asamblea se lleva a cabo en función de la 
iglesia de Antioquía, fundada y dirigida por los helenistas. En síntesis, Hechos 6,1 - 15, 35 es una sección con identidad propia, dedicada a la acción y misión de los helenistas. No es una sección puramente intermedia o de transición. Veamos algunas claves para interpetar los eventos más importantes de esta sección.

\section{Constitución del grupo de los siete helenistas: 6, 1-7}

En el v. 1 se mencionan dos grupos: los hebreos y los helenistas. En primer lugar, urge definir quienes eran estos helenistas. El consenso entre los estudiosos llega a la conclusión que eran judio-cristianos, de habla y cultura griega, residentes en Jerusalén (posiblemente originarios de la diáspora). Esto, sin embargo, no basta para explicar su actuación en los Hechos. Es necesaro agregar que los helenistas configuraban un grupo profético, crítico de la ley y del templo (léanse las acusaciones que se hacen contra Esteban y su discurso ante el sanedrin). Lucas presenta a Esteban lleno del Espíritu, discípulo fiel de Jesús, que muere como su maestro $(7,59-60)$. Los helenistas son también los perseguidos y dispersados el día que se desató la gran persecución contra la Iglesia de Jensalén después del martirio de Esteban $(8,2)$; son los mismos helenistas dispersados que anuncian la Palabra a los samaritanos $(8,4-8)$ y a los griegos $(11,19-21)$ y los que fundan la Iglesia en Antioquía. La sección que analizamos comienza con una asamblea en Jerusalén, donde se constituye el grupo de los siete $(6,1-7)$ y termina con otra asamblea en Jerusalén, donde se confíma la posición teológica de la Iglesia de Antioquía fundada por los helenistas (15, 1-35). El grupo de los hebreos, opuesto al de los helenistas, son judíos-cristianos, de habla aramea y de cultura tradicional hebrea. Lucas los presenta en los Hechos como fieles observantes de la ley, centrados en la vida cúltica del templo. Los sacerdotes (6, 7) y los fariseos $(15,5)$ que aceptan la fe son posiblemente de este grupo. Son los mismos que más tarde en Jerusalén son descritos como "los miles y miles de judios que han abrazado la fe y son todos celosos partidarios de la ley" $(21,20)$. Los doce apóstoles son presentados como parte de este grupo (véase la actitud de Pedro en el relato de Cornelio: 10, 14.28). Estos dos grupos ya habían sido insinuados en las personas de Bernabé y de Ananías y Safira (helenista el primero, y posiblemente hebreos los segundos).

Todo el relato de 6, 1-7 es incongruente y da la impresión de que Lucas oculta algo. Lucas nos narra, en primer lugar, una queja de los helenistas contra los hebreos, porque sus viudas eran desatendidas en la diakonla diaria. El sentido aparente del relato es que los apóstoles, al multiplicarse el número de los discípulos, no logran atender a todos los pobres. Por eso, Pedro propone a la asamblea, que se elijan siete hombres para servir a las mesas, y así poder dedicarse ellos totalmente a la palabra de Dios. Pero este relato aparente no convence, pues no se trata de un problema de descuido de todas las viudas, sino sólo de las viudas helenistas. No es, por lo tanto, un problema práctico de falta de servidores, sino un problema de discriminación de los helenistas. Además, es extraña la 
oposición entre diakonía de las mesas (v. 2) y diakonía de la palabra (v. 4). Por último, en lodo el relato de los capítulos 6 al 15 , los helenistas lo que menos hacen es servir a las mesas; se dedican más bien a la evangelización.

Una solución a estas incongruencias es que Lucas juntó aquí dos hechos históricos o tradiciones distintas. Una más antigua, referente al problema práctico del servicio a las mesas, y olra, posterior, del conflicto entre el grupo de los hebreos y los helenistas. La causa del conflicto no es sólo un problema de idioma, pues seguramente los hebreos hablaban griego y los helenistas también entendían el arameo. Tampoco el conflicto se explica por las dos culturas diferentes. Más bien sospechamos que en el relato de Lucas se trata de un conflicto más profundo: la defensa que hizo Gamaliel de los apostoles y el reconocimiento de ellos por parte del sanedrín $(5,34-41)$ posiblemente reforź al grupo de los hebreos en Jerusalén. La multiplicación de los discípulos en 6, I sería especialmente la multiplicación de los discípulos del grupo hebreo. Por eso también cuando estalla la persecución "todos, a excepción de los apóstoles, se dispersaron" $(8,1)$. La persecución es obviamente contra los helenistas. Adernás, en perspectiva histórica, podemos suponer que los helenistas son discriminados por los hebreos por su teología profética, crítica de la ley y del templo y por su misión en medio de samaritanos y griegos. Este es el conflicto de fondo que Lucas oculta en la apariencia del relato. La solución al conflicto, por lo tanto, no es nombrar servidores de las mesas para ayudar a los apóstoles, sino designar siete dirigentes para presidir el gnupo de los helenislas. Así como el grupo hebreo tiene su dirección en los doce, los helenistas tienen su dirección en los siete (en cierto paralelismo con Lucas 10 donde aparecen los 70 disclpulos en paralelo con los 12 apóstoles). En nigún lugar en el relato se dice que los siete son diakonos (se usa solamente el verbo diakonein y el sustantivo diakonia). Es más congruente con el conflicto de fondo y con el sentido de todo el relato (del capítulo 6 al 15) suponer en el grupo de los siete una "jerarquía" del grupo de los helenistas, tan importante como la "jerarquía" del grupo hebreo, constituida por los doce(13). La constitución del grupo de los siete helenistas, como grupo diferente, fue posiblemente lo que provocó la conversión de la "multitud de sacerdotes" en Jerusalén $(6,7)$. Una vez que hemos diferenciado los dos escenarios, el aparente y el profundo, podemos quizás imaginar un escenario de conciliación, que también es interesante: los siete habrían sido inicialmente escogidos para el servicio de las mesas, pero muy pronto ese servicio los habria llevado a un liderazgo mayor de todo el grupo de los helenistas y a la

13. Rius-Camps va más lejos y ve en el paralelismo entre los doce y los siete el mismo paralelismo entre Juan Bautista y Jesús. En todo caso, en los Hechos la posición de los doce está muy circunscrita a la ley y al templo de Jerusalén, excepto en Pedro. La tendencia general en la tradición del imaginario colectivo de la cristiandad es exaltar el grupo de los doce y reducir el rol de los "siete diakonos" helenistas. 
evangelización fuera de Jerusalén. La diakonía de las mesas los proyectó a la diakonia de la Palabra, la solidaridad con los pobres los llevó al servicio de la Palabra. No hay contradicción entre ambas cosas, pero, quizás, sí hay una sucesión en el tiempo.

En la estructura de Hechos 6, I - 15, 35, ya destacamos la unidad literaria y teológica de todas las secciones que hemos llamado "Hechos de los helenistas". En esa unidad y al servicio de ella, Lucas intercala los "Hechos de Saulo" (9, 131) y los "Hechos de Pedro" (9, 32 - 11, 18 y 12, 1-24). El texto 6, 1-7 es el texto inicial y lundante de todo este bloque de los helenistas. Lucas ha tenido mucho cuidado en unir redaccionalmente este bloque. Por ejemplo, 8, 1b (persecución en Jerusalén y dispersión de los helenistas), se une a 8, 4 ("los que se habfan dispersado"), que introduce la evangelización de los samaritanos por Felipe $(8,5-24)$, lo cual se une con 11,19 ("los que se habían dispersado cuando la tribulación originada a la muerte de Esteban"), que introduce la evangelización de los griegos por los ouros helenistas $(11,19-20)$. Igualmente, las dos frases paralelas y estructurantes en 8, 14 ("al enterarse los apóstoles que estaban en Jerusalén de que Samaría había aceptado la palabra de Dios, les enviaron a Pedro y Juan") y en 11, 22 ("la noticia de esto llegó a oldos de la Iglesia de Jerusalén y enviaron a Bernabé a Antioquía"). Lucas también agrega una serie de versículos, estilo resúmenes (con verbos en imperfecto), que dan mayor unidad a todo el relato de los helenistas: 6,$7 ; 8,25 ; 9,31 ; 11,21 ; 12,24 ; 13,1 ; 14,27$ y 15,35 . Vuelvo a insistir en que la sección 13,1-14, 28 pertenece a los helenistas: es la misión de la Iglesia de Antioquía. Bernabé y Pablo, como parte del grupo de profetas y maestros, que dirigen dicha comunidad, participan de la misión de la Iglesia. No se Irala del primer viaje de Pablo (los viajes misioneros de Pablo están en 15, $36-19,20$ ), sino todavfa de los "Hechos de los helenistas". Igualmente, pertenece a los helenistas la sección 15, 1-35, donde la Iglesia de Jerusalén confirma a la Iglesia de Antioquía. Aquí culmina el bloque de los "Hechos de los helenistas".

\section{Hechos de Esteban y Felipe: 6, 8 - 8, 40}

Esteban y Felipe, del grupo de los siete, así como Pedro y Juan lo son de los doce, son ahora los que abren el bloque de los Hechos de los helenistas. En la sección de Esteban tenemos una narrativa y un discurso. La narrativa comienza en 6,8-15 y continúa en 7,55-60. El texto está claramente intermumpido pur el discurso de 7, 1-54 (léase especialmente como una unidad 7, 55-56 a continuación de 6, 15, unidad que nos narra la transfiguración de Esteban). Lucas introduce a Saulo al final del relato de Esteban $(7,58 b ; 8,1 \mathrm{a} ; 8,3)$. Se trata claramente de un agregado redaccional a una tradición o fuente más antigua. Como ya dijimos, los dispersados en la persecución en el día de la muerte de Esteban son los helenistas, no los apóstoles. Uno de ellos es Felipe. Los Hechos de Felipe los tenemos en 8, 5-40 y la noticia en $21,8-9$, donde se menciona por úluma vez a 
Felipe, como evangelista y uno de los siete, que reside en Cesarea y liene cuatro hijas vírgenes que profetizaban. En estos Hechos de Felipe hay dos momentos contrapuestos. El primero nos narra la evangelización en la ciudad de Samaría, donde hace muchas señales y milagros y tiene mucho éxito; incluso el mago de la ciudad, Simón, creyó y fue bautizado. Pero este primer momento misionero es insuficiente y termina con un fracaso. En la evangelización masiva y extraordinaria de Felipe todavía no había Espíritu Santo. Este llega sólo con la visita de Pedro y Juan desde Jerusalén. El gran triunfo de Felipe, que era Simón el mago, creyente y bautizado, cree más en el poder del dinero y busca comprar el don del Espíritu. Es un rotundo fracaso para Felipe. Por eso, Lucas nos narra un segundo momento en la evangelización de Felipe. Ahora no va al norte, sino al sur; no a una ciudad, sino al desierto; no a evangelizar multitudes, sino a una sola persona: el eunuco ellope. Felipe ya no hace señales y milagros, sino que se pone a caminar con el eunuco y a escuchar lo que iba leyendo. Felipe ahora anuncia la buena nueva de Jesús a partir del texto que el etíope iba leyendo. Felipe está ahora imitando exactamente el método que utilizó Jesús con los discípulos de Emaús (Lc 24). Felipe se deja primero conducir por el Espíritu (v. 29) y después es arrebalado por el mismo Espíritu (v. 39).

\section{Los helenistas fundan la Iglesia de Antioquía: 11, 19-30}

El texto 11,19 se conecta directamente con $8,1.4$, donde se habla de los dispersados en la persecución originada a la muerte de Esteban(14). Aqư no se mencionan nombres, sino "algunos chipriotas y cirenenses", que son ciertamente del grupo de los helenistas. La gran novedad aquí es que en Antioquía "hablaban a los griegos y les anunciaban la Buena Nueva de Jesús" y "un crecido número recibió la fe y se convirtió al Señor" (vv. 20-21). Igual que en 8, 14 (después de la novedad de la evangelización de los samaritanos), también ahora la noticia llega a "la Iglesia de Jerusalén" y envían a Bernabé. Este reconfirma la fe de la comunidad de los discípulos, y en vez de volver a Jerusalén va a Tarso a buscar a Saulo. En el v. 24 lenemos una alabanza de Bernabé, como "hombre bueno, lleno de Espíritu Santo y de fe". El éxito en Antioquía fue grande, con el apoyo de Bernabé y Saulo, y ahí "por primera vez, los discípulos recibieron el nombre de "cristianos" (v. 26). La comunidad recibe la visita de unos profelas de Jerusalén, entre ellos el profeta Agabo (vv. 27-28). Estos no son enviados por las autoridades de Jerusalén, sino que actúan "movidos por el Espíritu". Una actividad profética parecida encontramos en las comunidades de Tiro y Cesarea (21, 3-12). El profeta Agabo anuncia que vendría "una gran hambre sobre toda la tierra". Esta acaeció en los años 46-48, lo que implica un error cronológico, pues el relato del capítulo siguiente sucede entre el 41 y $44 \mathrm{~d}$. C., cuando el rey Herodes Agripa gobiema

14. El verbo diaspeiro (dispersar) aparece en Hechos únicamente en 8,14 y $11,19$. 
sobre toda la Palestina. Lo importante es que la comunidad "cristiana" de Antioquía envía recursos en solidaridad con los hermanos de Judea. La misión de solidaridad es realizada por Bernabé y Saulo. Esta misión se narra en 11, 30 (ida a Jerusalén) y en 12, 25 (regreso de Jerusalén), enmarcando 12, 1-24, donde se narran varias noticias de Jerusalén. Este viaje de Pablo a Jerusalén no está contabilizado en el registro tan exacto de Pablo en su carta a los Gálatas (primera visita: Gal 1, 18, en el año 38; segunda visita: Gal 2, 1, en el año 48). Lucas, por otro lado, no menciona en la visita de Pablo a Jerusalén, al término de su misión, (Hechos 21, 16ss, en el año 56) la colecta de Pablo para esa Iglesia. Esta colecta de Pablo, mencionada con fuerza en sus cartas, es ciertamente histórica. Quizás Lucas confundió ambas visitas. En todo caso, aquí lo importante es ese gesto de solidaridad profética de los helenistas de la Iglesia "cristiana" de Antioquía con los hermanos hebreos (judeo-cristianos) de Jerusalén. La unidad de la Iglesia se construye a partir de la solidaridad en momentos de hambre.

\section{Misión de la Iglesia de los helenistas: 13, 1 - 14, 28}

En el comienzo $(13,1-3)$ y en el final $(14,27-28)$ de esta sección aparece la Iglesia de Antioquía como una Iglesia que está reunida, que envía al equipo misionero que ha elegido el Espíritu Santo y que al terminar la misión los recibe para escuchar su informe(15). Es la Iglesia la responsable de la misión. Como ya dijimos, no se trata del primer viaje misionero de Pablo, sino de la misión de la Iglesia de Antioquía. En la Iglesia fundada en Antioquia había "profelas y maestros". No se habla de "presbíteros" como en la Iglesia de Jerusalén $(15,2)$. Los cinco que se mencionan configuran una dirección eclesial bastante plural: Bemabé, levila originario de Chipre $(5,36)$; Simeón, nombre arameo, con el sobrenombre latino de Niger, que lo identifica como negro; Lucio, nombre latino, procedente del norte de Africa (Cirenaica); Menahén, hermano de leche de Herodes, y Saulo, fariseo de Tarso. Es el Espiritu Santo el que directamente elige a Bernabé y Saulo para la misión (v. 2) y el que los envía (v. 4). Es un equipo del Espíritu.

La misión comienza con un enfrentamiento cargado de simbolismos (13,612). Por un lado, un falso profeta judío llamado Bar Jesús (literalmente: discípulo de Jesús); por otro lado, Saulo, que lleno del Espiritu Santo, lo llama discípulo del diablo. Pablo lo deja ciego, como él había quedado ciego camino a Damasco, cuando se encuentra con Jesús $(9,8)$. Este enfrentamiemto tiene como fruto la conversión del procónsul Sergio Paulo. Aquí hay una clara contraposición de dos figuras simbolicas: Bar Jesús, quien representa el falso profetismo judio,

15. La palabra "Iglesia" aparece aqu[, en 13, 1 y 14, 27, haciendo ung inclusión. También aparece en 14, 23, en un giro distinto. Igualmente, la palabra "obra" se repite en 13, 2 y $14,26$. 
que pone obstáculos a la evangelización, y el procónsul Sergio Paulo, símbolo del mundo gentil "desesoso de escuchar la palabra de Dios". Saulo reconoce en BarJesús lo que él mismo había sido antes de su conversión y lo deja ciego, como él quedó ciego después de encontrarse con Cristo; el mismo Saulo se cambia el nombre y se hace llamar con el nombre del procónsul romano. Pablo rompe así con su propio pasado y se identifica con el mundo gentil, deseoso de escuchar a Dios. Pablo sigue viviendo en la misión el proceso de su propia conversión.

El punto culminante de la misión se da en Antioguía de Pisidia (13, 13-52). Aquí escuchamos el discurso de Pablo en la sinagoga. Es un discurso compuesto por Lucas, pero refleja lielmente el tipo de discurso que históricamente fue dirigido a los judíos de parte de los helenistas de la iglesia de Antioquía. Pablo participa de la misión de esła Iglesia. La sección final (vv. 44-52) es programática: la palabra de Dios ha sido dirigida, en primer lugar a los judíos, pero, como ellos la rechazan, los misioneros se vuelven a los gentiles. Sigue la alegría de los gentiles y la persecución de parte de los judfos incrédulos. Cuando los misioneros regresan a la Iglesia de Antioqula que los había enviado, cuentan "cómo Dios habia abierto a los gentiles la puerta de la fe" $(14,27)$.

\section{La asamblea de Jerusalén confirma a la comunidad de Antioquía: 15, 1-35}

Todo este capítulo está centrado en la Iglesia de Antioquía: es ahí donde surge el conflicto (vv. 1-2) y es a esta Iglesia que se dirige la carta de los apóstoles y presbiteros de Jerusalén (vv. 30-35). La asamblea de Jerusalén se realiza en función de los hermanos venidos de la gentilidad que están en Antioquía. Veamos algunas claves de interpretación.

Sucitado el conflicto en Antioquía, Pablo y Bernabé son enviados por la Iglesia a Jerusalén (v.3). Ya en 13, 3, la Iglesia habŕa enviado el mismo equipo, elegido directamente por el Espíritu Santo. Los enviados atraviesan Fenicia y Samaría, territorio ya evangelizado por los helenistas (en 11, 19: Fenicia y en 8, 5ss: Samaría), "contando la conversión de los gentiles". Cuando llegan a Jerusalén ya no informan sobre la conversión de los gentiles, sino únicamente "cuanto Dios habla hecho juntamente con ellos" (en 14, 27 cuentan ambas cosas a la Iglesia de Antioquía). Enviados por la Iglesia helenista de Antioqula son recibidos por la Iglesia hebrea de Jerusalén (los apóstoles y presbíteros). En la asamblea se dan dos discursos, el de Pedro y el de Santiago. Pedro trata tres temas: el Espíritu Santo ha sido dado a los gentiles lo mismo que a los apóstoles; Dios no hace discriminación entre los gentiles y los apóstoles, pues por la fe (y no por la ley) Dios purifica los corazones de los gentiles. Luego Pedro hace dos constataciones: la ley es una carga insoportable para los gentiles y judíos cristianos, así como para los judíos mismos, y "nosotros creemos que nos salvamos por la gracia del Señor Jesús, del mismo modo que ellos" (v. 11). Con esta 
segunda constatación, Pedro va más allá del tema discutido: la salvación de los judíos es del mismo modo que la salvación de los gentiles. La salvación de los paganos es el paradigma de salvación para los judlos. Los gentiles reciben el Espíritu como los apóstoles, pero los apóstoles (es decir, los judíos) son salvos como los gentiles, es decir, al margen de la ley. Cuando Pedro termina su discurso, la asamblea calló y escuchaban a Bernabé y Pablo (en ese orden los había elegido el Espíritu en 13, 1-3). Es cuando terminan de hablar que toma la palabra Santiago, el cual tiene que pedir que lo escuchen.

Santiago comienza su discurso, resumiendo, pero a la vez distorsionando, el discurso de Pedro (al cual llama Simeón). Para Pedro el paradigma de salvación para los judios es la salvación de los gentiles; ahora Santiago subordina los gentiles a la causa de los judios ( $v$. 14) y subordina igualmente la salvación de los gentiles a la restauración de Israel (vv. 15-18). Santiago invierte el razonamiento de Pedro. Después de su discurso, Santiago dicta sentencia, en forma bastante autoritaria: "Por esto decido, juzgo yo" (dio ego krino: v. 19). La asamblea adquiere carácter de juicio: Bernabé y Pablo aparecen como acusados, Pedro hace la defensa, Bernabé y Pablo aportan las pruebas (v. 12) y Santiago dicta la sentencia. En su sentencia, Santiago decide que ya no se moleste a los gentiles convertidos, que solamente se les aplique el estatuto jurfdico exigido a los paganos que viven en territorio judio: abstenerse de la carne inmolada a los ídolos, de relaciones sexuales ilícitas, de comer carne de animales estrangulados y de comer sangre (vv. 19-20). Santiago afirma la vigencia permanente de ley (v. 21) y no quiere que los gentiles cristianos influyan negativamente en los judíos cristianos, para que éstos dejen de observar la ley. Pedro, por el contrario, habla propuesto una libertad total frente a la ley, tanto para los gentiles como para los judíos creyentes (nosotros judíos creyentes somos salvos igual que ellos gentiles creyentes: cfr. v. 11).

Los apóstoles y presbíteros, de acuerdo con toda la Iglesia, deciden enviar una carta a los gentiles cristianos de Antioquía, Siria y Cilicia. Lo que deciden es, en realidad, sólo lo que ya Santiago ha decretado y sentenciado. No se discute nada. La opinión de Pedro es dejada completamente de lado. Hay una decisión de común acuerdo (homothumadon: v. 25) de elegir a Judas y Silas para enviarlos junto con Bernabé y Pablo; pero la decisión sobre lo que se debe exigir a los gentiles cristianos es una decisión compartida: "hemos decidido el Espíritu Santo y nosotros" (v. 28). Para Lucas, y para el lector de los Hechos, Pedro ha representado la opinión del Esplritu Santo de proclamar la libertad frente a la ley, y Santiago con los presbíteros de Jerusalén es el "nosotros" que decide mantener la vigencia de la ley. La carta es recibida con gozo en Antioqufa, pero Judas y Silas que eran profetas, tuvieron que exhortar con un largo discurso a los hermanos y confortarlos; también Pablo y Bernabé se quedaron en Anlioquía, enseñando y anunciando la Buena Nueva y la palabra del Señor. Con todo esto, la Iglesia de los helenistas fue confirmada en su identidad y en su fe. Aquí 
Lucas da por terminada la sección dedicada a los helenistas (de 6, 1 hasta 15, 35).

\section{Conclusión}

El libro de los Hechos rescata para nosotros el tiempo histórico posterior a la resurrección de Jesús y anterior a la institucionalización de la Iglesia. En este tiempo originario y fundante, el movimiento de Jesús se organiza en pequeñas comunidades domésticas y es impulsado por los misioneros itinerantes; es un movimiento del Espíritu y un movimiento misionero. Hoy día debemos volver a reconstruir este tiempo histórico, para reconstruir nuestra identidad eclesial desde sus orfgenes. Con este fin hemos introducido a una lectura actualizada de los Hechos de los apóstoles. Debemos seguir leyendo los Hechos con el mismo Espíritu con que fue escrito. En un próximo artículo daremos las claves de interpretación para leer la tercera parte de estos Hechos de los apóstoles (de 15 , 36 hasta 28,31 ). 